\title{
Microorganisms Aerobically Degrading Skatole or Indole in Composting Processes
}

\author{
Yutaka NAKAI, Takashi NIINO, Tasuke ANDO and Chikara KOHDA \\ Faculty of Agriculture, Tohoku University, Aoba-ku, Sendai-shi 981-8555, Japan
}

(Received April 27, 1998 ; Accepted October 30, 1998)

\begin{abstract}
The concentrations of skatole (3-methylindole) and indole were determined in the manure in chicken or pig waste composting processes, and microorganisms that aerobically degrade these indolic compounds were isolated. The concentration of skatole in the manure decreased as the treatment progressed in both composting processes. The concentration of indole decreased largely at the fermentation stage in the pig waste composting system; however, that was almost stable in the chicken waste composting system. The numbers of total aerobes and skatole- or indole-degrading microbes decreased at the fermentation stage and increased again at the finishing stage in both composting systems. In the chicken waste system, the largest number of skatole- and indole-degrading microbes was occupied by facultatively anaerobic gram-positive cocci at the pretreatment and fermentation stages, and by aerobic gram-positive cocci at the finishing stage. In the pig waste system, that was occupied by facultatively anaerobic gram-positive cocci at any stage. Enzyme preparations which were extracted from cultures of skatole-degrading isolates or indole-degrading isolates showed degradation activities of skatole or indole, respectively.
\end{abstract}

Animal Science Journal 70 (1) : 32-37, 1999

Key words : Biodegradation, Compost, Indole, Manure, Skatole

Composting has been widely used as an animal manure treatment system, and is effective methods for manure recycling ${ }^{15)}$. Recently, unpleasant smell from composting facilities is an important issue of a nuisance. Indole and its derivatives such as skatole (3-methylindole) are major malodorous compounds in the feces and sewage, and resistant to degradation ${ }^{3,4}$. Although some microorganisms have been known to degrade these indolic compounds ${ }^{1,2,6.7,11,13)}$, a few studies were performed for microbes in composting processes $^{15)}$. We had isolated anaerobic microbes from composting processes, and made clear their ability to degrade indolic compounds anaerobically ${ }^{9,10)}$. Although the composting is widely believed to be an aerobic system of waste treatment, the aerobic degradation of indolic compounds in composting processes has not been clarified yet.

In the present study, we observed the change of skatole and indole in the manure in composting processes. We also investigated microbes which aerobically degraded these indolic compounds in composting processes.

\section{Materials and Methods}

\section{Sample}

Samples were obtained from a chicken waste composting system and a pig waste composting system as mentioned previously9). The water content of manure $(\%)$ at the pretreatment, fermentation, and finishing stage was 51.6, 61.3 and 20.1 in the chicken waste composting system, and 59.6, 63.0 and 24.9 in the pig waste composting system, respectively. Temperature of the manure $\left({ }^{\circ} \mathrm{C}\right)$ at each stage was 50,60 and 20 in the chicken waste composting system, and 40,75 and 20 in the pig waste composting system, respectively.

Corresponding : Yutaka NAKAI (fax : +81 (0) 22-717-8710, e-mail : nakai@bios.tohoku.ac.jp)

Anim. Sci. J. 70 (1) : 32-37, 1999 
Aerobic Biodegradation of Skatole in Compost

\section{Measurement of skatole or indole}

Concentrations of skatole and indole were measured by gas chromatography as mentioned previously ${ }^{10)}$.

\section{Bacterial count}

Aerobic microbes were counted by 10 -fold dilution methods using a sterilized saline and a cultivation on trypticase soy agar plates added with $10 \%$ compost extracted solution. The compost extracted solution was prepared as described by Gordon and Rynearson ${ }^{5)}$. The solution extracted from the chicken or pig waste compost was used for cultivation of microbes from the chicken or pig waste composting system, respectively. The number of skatole or indole-degrading aerobic microbes was determined by colony counts on media which contained skatole or indole as a sole source of carbon, respectively. The media contained the following nutrients; skatole or indole $0.3 \mathrm{~g}, \mathrm{NaCl} 0.1 \mathrm{~g}, \mathrm{KH}_{2} \mathrm{PO}_{4} 0.5 \mathrm{~g}, \mathrm{KHPO}_{4} 1.5 \mathrm{~g}$, $\mathrm{MgSO}_{4} 0.35 \mathrm{~g}$, agar $15 \mathrm{~g}$, (pH 7.0) in 11 of water. Skatole and indole were dissolved in a minimum amount of methanol and added to the autoclaved medium as previously mentioned ${ }^{9)}$. Typing of microbes were performed by the methods of Mitsuoka et al. ${ }^{12)}$. These cultures were incubated 7 days at room temperature $\left(25-30^{\circ} \mathrm{C}\right)$ or $37^{\circ} \mathrm{C}$.

\section{Enzyme activity}

Among microbes aerobically degrading skatole, three isolates were chosen; i.e. SC-54 (facultatively anaerobic gram-positive coccus), SP-06 (facultatively anaerobic gram-positive endospore-forming rod), and SC-53 (facultatively anaerobic gram-positive endospore-forming rod). Among microbes aerobically degrading indole, three isolates were chosen; i.e. IC55 (facultatively anaerobic gram-positive coccus), IP03 (aerobic gram-positive coccus), and IC-53 (aerobic gram-positive endospore-forming rod). SC-54, SC53, IC-55 and IC-53 were isolated from the chicken waste composting process, and SP-06 and IP-03 were isolated from the pig waste composting process. Isolates were incubated in trypticase soy broth for $42 \mathrm{~h}$ at $37^{\circ} \mathrm{C}$. The culture media and microbes were Frenchpressed together, and centrifuged at $10,000 \times g$ and the supernatant was filtrated through $0.45 \mu \mathrm{m}$ millipore filter. Skatole and indole was added to the filtrate at the final concentration of $30 \mathrm{mg} / l$. Concentrations of skatole and indole were determined after incubation at $37^{\circ} \mathrm{C}$ for $42 \mathrm{~h}$

\section{Results}

Decomposition of skatole and indole in the waste composting processes

Figure 1 showed the concentrations of skatole and indole in the manure in the composting processes. In the chicken waste composting system, concentration of skatole decreased as the treatment progressed, and that of indole was almost stable in the process. In the pig waste composting system, concentration of skatole decreased as the treatment progressed; however, that of indole decreased largely at the fermentation stage and was stable after that stage. Although the concentration of these indolic compounds was higher in the pig waste than that in chicken one at the pretreatment stage, the concentration of these compounds was similar level at the finishing stage.

\section{Microbes aerobically degrading skatole or indole in} the composting systems

Figure 2 showed the numbers of aerobic microbes in the standard culture plate which did not contain any indolic compounds. The numbers decreased at the fermentation stage and increased again at the finishing stage in both composting systems. We tried to detect microbes at two cultivation temperature, i.e. room tempcrature as the environmental condition and $37^{\circ} \mathrm{C}$

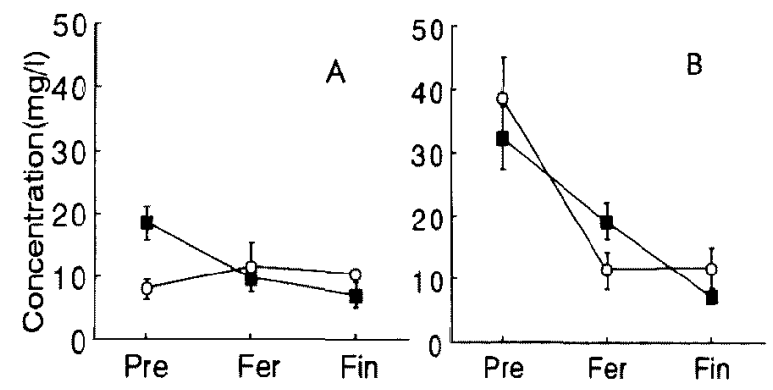

Fig. 1. Concentrations of skatole ( $\square$ ) and indole (O) in the composting processes of chicken waste (A) and pig waste (B). Samples were collected from the pretreatment stage (Pre), the fermentation stage (Fer) and the finishing stage (Fin). The concentrations of indolic compounds were measured as described in the text. 

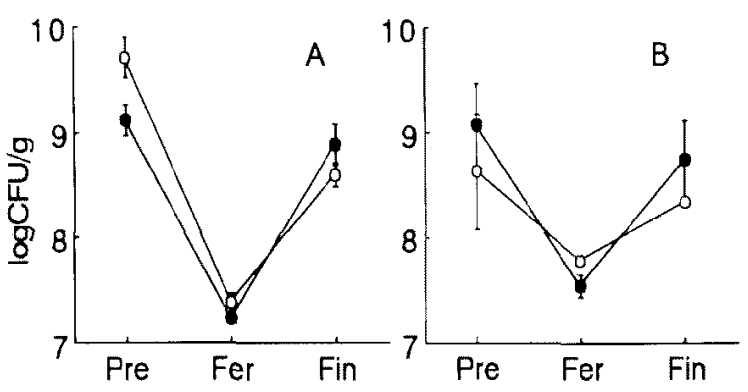

Fig. 2. Numbers of aerobes in the composting processes of chicken waste (A) and pig waste (B). Samples were collected from the pretreatment stage (Pre), the fermentation stage (Fer) and the finishing stage (Fin), and cultivated on the standard culture plates without any indolic compounds at room temperature $\left(25-30^{\circ} \mathrm{C}: \bigcirc\right)$ or at $37^{\circ} \mathrm{C}(\mathrm{O})$.

as the excreted fecal condition. There was little difference between the number in the culture at room temperature and the number at $37^{\circ} \mathrm{C}$ at each stage.

Microbes which aerobically degrade skatole or indole were detected from all stages of composting (Fig. 3). The numbers of skatole- or indoledegrading microbes decreased at the fermentation stage and increased again at the finishing stage in both composting systems. The number of skatoledegrading microbes and that of indole-degrading microbes were similar levels at each stage. There was little difference between the number in the culture at room temperature and the number at $37^{\circ} \mathrm{C}$ at each stage in the chicken waste composting; however, in the pig waste composting relatively larger numbers were observed in the culture at $37^{\circ} \mathrm{C}$ than at room temperature at the fermentation stage and the finishing stage. The numbers of skatole- or indoledegrading microbes were in the range of $1 / 1,000$ to $1 /$ 100,000 of the number of aerobes in the standard culture at each stage.

Types of microbes aerobically degrading skatole or indole

Types of microbes degrading these indolic compounds were investigated among colonies. In the chicken waste composting (Table 1), skatole degrading microbes were classified into 3 types, i.e. facultatively anaerobic gram-positive cocci, aerobic gram-positive cocci, and facultatively anaerobic gram-

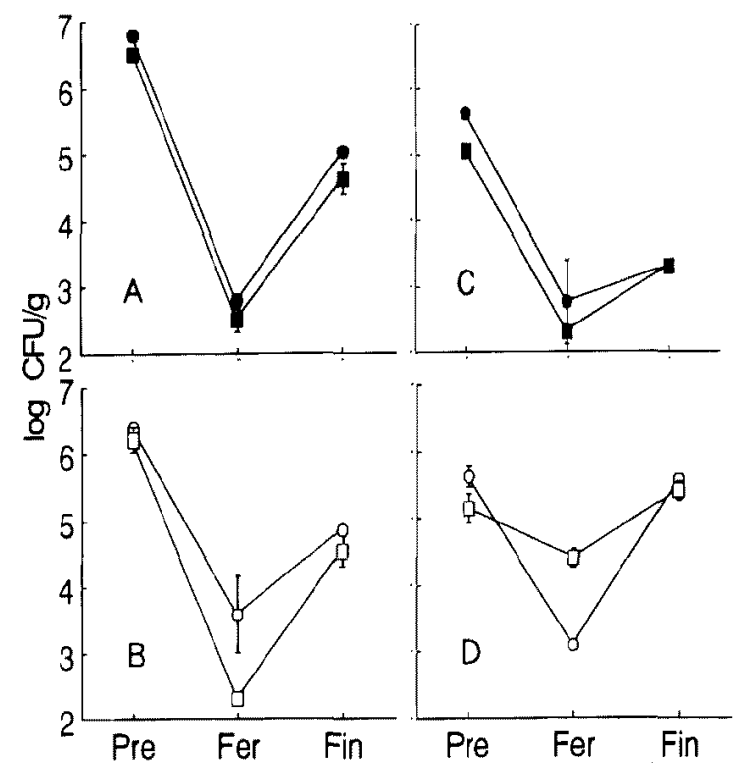

Fig. 3. Numbers of microbes aerobically degrading skatole $(\square, \square)$ or indole $(\boldsymbol{O}, \bigcirc)$ in the composting processes of chicken waste $(\mathrm{A}, \mathrm{B})$ and pig waste $(C, D)$. Samples were collected from the pretreatment stage (Pre), the fermentation stage (Fer) and the finishing stage (Fin), and were cultivated on the plates containing skatole or indole at room temperature $\left(2530^{\circ} \mathrm{C}: \boldsymbol{\square}, \boldsymbol{O}\right)$ or at $37^{\circ} \mathrm{C}$ $(\square, \bigcirc)$.

positive endospore-forming rods. Indole-degrading microbes were classified into 2 types, i.e. facultatively anaerobic gram-positive cocci and aerobic grampositive endospore-forming rods. At the pretreatment and fermentation stages, facultatively anaerobic gram-positive cocci were the largest in number among both skatole- and indole-degrading microbes. At the finishing stage, aerobic gram-positive cocci or aerobic gram-positive endospore-forming rods were the largest in number among skatole- or indole-degrading microbes, respectively.

In the pig waste composting (Table 2), 3 types of skatole degrading microbes were detected, i.e. facultatively anaerobic gram-positive cocci, aerobic gram-positive cocci, and facultatively anaerobic grampositive endospore-forming rods. Indole-degrading microbes were classified into 3 types, i.e. facultatively anaerobic gram-positive cocci, aerobic gram-positive cocci and aerobic gram-positive endospore-forming 
rods. Facultatively anaerobic gram-positive cocci were the largest in number at any stage among both skatole- and indole-degrading microbes.
Neither of gram-negative bacteria, actinomycetes or fungi were detected at any stage in the chicken and pig composting systems among microbes degrading

Table 1. Types of microbes aerobically degrading skatole or indole in the chicken waste composting process

\begin{tabular}{|c|c|c|c|c|c|c|}
\hline \multirow{2}{*}{ Types of microbes ${ }^{1)}$} & \multicolumn{2}{|c|}{$\begin{array}{l}\text { Pretreatment } \\
\text { stage }\end{array}$} & \multicolumn{2}{|c|}{$\begin{array}{c}\text { Fermentation } \\
\text { stage }\end{array}$} & \multicolumn{2}{|c|}{ Finishing stage } \\
\hline & Number $^{2)}$ & $\%^{3)}$ & Number & $\%$ & Number & $\%$ \\
\hline \multicolumn{7}{|l|}{$\begin{array}{l}\text { Skatole-degrading } \\
\text { microbes }\end{array}$} \\
\hline FPC & 5.90 & 48.3 & 2.10 & 62.5 & 4.05 & 32.8 \\
\hline $\mathrm{APC}$ & 5.50 & 19.0 & 1. 40 & 12.5 & 4.35 & 67.2 \\
\hline FPER & 5.74 & 32.8 & 1.70 & 25.0 & 3.23 & 5.0 \\
\hline \multicolumn{7}{|l|}{$\begin{array}{l}\text { Indole-degrading } \\
\text { microbes }\end{array}$} \\
\hline FPC & 6.25 & 74.1 & 3.56 & 95.0 & 4.25 & 25.0 \\
\hline APER & 5.86 & 28.6 & 2.28 & 5.0 & 4.73 & 75.0 \\
\hline
\end{tabular}

1) FPC, facultatively anaerobic gram-positive cocci; APC, aerobic gram-positive cocci ; FPER, facultatively anaerobic gram-positive endospore-forming rods ; APER, aerobic gram-positive endospore-forming rods.

2) Mean of $\log \mathrm{CFU} / \mathrm{g}$ of the manure wet weight.

3) $\%$ of the total number of skatole- or indole-degrading microbes.

Table 2. Types of microbes aerobically degrading skatole or indole in the pig waste composting process

\begin{tabular}{|c|c|c|c|c|c|c|}
\hline \multirow{2}{*}{ Types of microbes ${ }^{1)}$} & \multicolumn{2}{|c|}{$\begin{array}{l}\text { Pretreatment } \\
\text { stage }\end{array}$} & \multicolumn{2}{|c|}{$\begin{array}{l}\text { Fermentation } \\
\text { stage }\end{array}$} & \multicolumn{2}{|c|}{ Finishing stage } \\
\hline & Number ${ }^{2)}$ & $\%^{3)}$ & Number & $\%$ & Number & $\%$ \\
\hline \multicolumn{7}{|l|}{$\begin{array}{l}\text { Skatole-degrading } \\
\text { microbes }\end{array}$} \\
\hline FPC & 4.78 & 42.4 & 4. 34 & 88.1 & 5.34 & 88.0 \\
\hline $\mathrm{APC}$ & 4. 49 & 21.8 & 2.94 & 3.5 & 4. 40 & 10.0 \\
\hline FPER & 4.70 & 35.4 & 3.32 & 8.4 & 3.70 & 2.0 \\
\hline \multicolumn{7}{|l|}{$\begin{array}{l}\text { Indole-degrading } \\
\text { microbes }\end{array}$} \\
\hline FPC & 5.30 & 46.3 & 3.01 & 84.7 & 5.31 & 54.5 \\
\hline $\mathrm{APC}$ & 4.81 & 14.9 & 0 & 0 & 0 & 0 \\
\hline APER & 5.22 & 38.8 & 2.26 & 15.3 & 5.23 & 45.5 \\
\hline
\end{tabular}

1) FPC, facultatively anaerobic gram-positive cocci ; APC, aerobic gram-positive cocci; FPER, facultatively anaerobic gram-positive endospore-forming rods ; APER, aerobic gram-positive endospore-forming rods.

2) Mean of $\log \mathrm{CFU} / \mathrm{g}$ of the manure wet weight.

3) $\%$ of the total number of skatole- or indole-degrading microbes. 
skatole or indole.

\section{Enzyme activity}

The enzyme activity of crude extract of cultures of isolates was measured (Table 3). As the concentration of the substrates, $30 \mathrm{mg} / l$ of skatole or indole which was as high as their concentration at the pretreatment stage of the pig waste composting system was used. Extracts of cultures of microbes which were isolated from the skatole medium degraded 9.0 $20.4 \%$ of skatole as the substrate, and that from the indole medium degraded $19.6-34.1 \%$ of indole. The results directly indicated that these isolates had the ability to degrade these indolic compounds.

\section{Discussion}

The concentrations of skatole or indole in the manure especially in the pig waste composting process decreased as the treatment progressed (Fig. 1). It suggests that these indolic compounds were degraded through the composting process. Higher numbers of microbes degrading skatole or indole were observed at the pretreatment stages (Fig. 3). They may degrade indolic compounds during the stage from pretreatment to fermentation. Their numbers decreased in the fermentation stages and increased again in the finishing stages (Fig. 3) accompanied by the change of the number of aerobes (Fig. 2). Such a pattern was commonly observed for mesophilic bacteria in composts $^{15)}$. These results indicate that skatole- or indole-degrading microbes exist constantly in the mesophilic microbial flora in the composting process.

Skatole- or indole-degrading microbes were larger in number in the culture at $37^{\circ} \mathrm{C}$, compared with those

Table 3. Enzyme activity of crude extract of cultures of isolates

\begin{tabular}{lcc}
\hline \hline Isolate & Substrate & Substrate degradation rate $(\%)$ \\
\hline SC-54 & Skatole & 11.7 \\
SP-06 & Skatole & 20.4 \\
SC-53 & Skatole & 9.0 \\
& & \\
IC-55 & Indole & 34.1 \\
IP-03 & Indole & 19.6 \\
IC-53 & Indole & 20.7 \\
\hline
\end{tabular}

Anim. Sci. J. 70 (1) : 32-37, 1999 at room temperature at the fermentation and finishing stages in the pig waste composting process. The temperature at the fermentation stage in the pig waste composting process was $75^{\circ} \mathrm{C}$, which was relatively high in common composting systems. This results may suggest the selection of microbes which can survive under the higher temperature. Although no thermophilic microbes which anaerobically degrade skatole or indole were detected in the composting processes ${ }^{9}$, we should investigate the thermophilic microbes which aerobically degrade these indolic compounds in the future work.

Facultatively anaerobic gram-positive cocci were dominant at the pretreatment and fermentation stages in both composting systems and also at the finishing stage in the pig waste composting system. Our previous work ${ }^{9)}$ showed that 67 to $91 \%$ were facultative anaerobes among microbes which anaerobically degrade skatole or indole in the composting systems. Neither of gram-negative bacteria, actinomycetes or fungi were detected among microbes degrading skatole or indole under the aerobic condition in this study and the anaerobic condition ${ }^{9)}$. Therefore, facultatively anaerobic bacteria may dominantly degrade skatole and indole aerobically and anaerobically at the early stages of the composting processes. Composts are generally in aerobic conditions ; however, anaerobic conditions prevail in the interior of composts under some circumstances ${ }^{8,14)}$. Therefore, facultatively anaerobic bacteria may have the advantage over aerobes or anaerobes in the composting process.

In the chicken waste composting, aerobic gram positive microbes instead of facultative anaerobes were dominant at the finishing stage. There are many factors affecting microbial dominancy, e.g. water components, air flow, fermentation temperature or contents of waste. The mechanisms of the selection of microbes should be determined under the laboratory condition in the future study.

\section{Acknowledgments}

This study was partly supported by a Grant-in-Aid (Nos. 06760292 and 07555460) for Scientific Research from the Ministry of Education, Science, Sports and 
Aerobic Biodegradation of Skatole in Compost

Culture, Research Grants for Meat and Meat Products from the Ito Foundation, and a Grant in Aid for Scientific Research from the Ministry of Health and Welfare and Japan Education Center of Environmental Sanitation.

\section{References}

1) Bak F, Widdel F. Anaerobic degradation of indolic compounds by sulfate-reducing enrichment cultures, and description of Desulfobacterium indolicum gen. nov. Archives of Microbiology, $146: 170-176.1986$.

2) Berry DF, Madsen EL, Bollag JM. Conversion of indole to oxindole under methanogenic conditions. Applied and Environmental Microbiology, 53 : 180182. 1987.

3) Bethea RM, Narayan RS. Identification of beef cattle feedlot odors. Transactions of the American Society of Agriculturally Engineering, 15 : 1135-1137. 1972.

4) Burnett WE. Air pollution from animal waste : determination of malodors by gas chromatography and organoleptic techniques. Journal of the Faculty of Environmental Science and Technology, 3 : 744-749. 1969.

5) Gordon RE, Rynearson TK. Maintenance of strain of Bacillus species. In : Culture Collections: Perspectives and Problems. (Martin SM ed.) 118-128. University of Toronto Press. Toronto. 1962.

6) Gu JD, Berry DF. Metabolism of 3-methylindoles by a methanogenic consortium. Applied and Environmental Microbiology, 58 : 2667-2669. 1992.

7) Kamath AV, Vaidyanathan CS. New pathway for the Biodegradation of indole in Aspergillus niger. Applied and Environmental Microbiology, $56: 275-$ 280. 1990.
8) Kochtilzky OW, Seaman WK, Wiely JS. Municipal composting research at Johnson city, Tennessee. Science and Engineering of Composting, 9:5-16. 1969.

9) Kohda C, Ando T, Nakai Y. Anaerobic microorganisms degrading 3-methylindole (skatole) and indole in composting processes. Animal Science and Technology, 68 : 1045-1051. 1997.

10) Kohda C, Ando T, Nakai $Y$. Isolation and characterization of anaerobic indole- and skatole-degrading bacteria from composting animal wastes. Journal of General and Applied Microbiology, $43: 249-255$. 1997.

11) Madesen EL, Bollag JM. Pathway of indole metabolism by a denitrifying microbial community. Archives of Microbiology, 151 : 71-76. 1989.

12) Mitsuoka $T$, Ohno $K$, Benno $Y$, Suzuki $K$, Nanba $K$. Die Faekalflora bei Menschen. IV. Mitteilung Vergleich des neu entwickelten Berfahrens mit dem bisherigen üblichen Verfahren zur Darmfloraanalyse. Zentralblatt für Bakteriologie, Parasitenkunde und Infectionskrank Hygen. Abteilung 1, Originale, A $234: 219-233.1976$.

13) Muler HE. Production and degradation of indole by gram-negative bacteria. Zentralblatt für Bakteriologie, Parasitenkunde, Infektionskranheiten und Hygiene, A $261: 1-11.1986$.

14) Wiley JS, Spillane JT. Refuse-sludge composting in windrows and bins. Science and Engineering of Composting, $2: 18-25.1962$.

15) Zibilske LM. Composting of organic wastes. In : Principles and Applications of Soil Microbiology. (Sylvia DM, Fuhrmann JJ, Hartel PG, Zuberer DA eds.) 482-497. Prentice-Hall, Inc. New Jersey. 1998. 